\title{
Edificação Modular: Estudo de caso e protótipo de um sistema construtivo de código aberto utilizando prototipagem rápida
}

\author{
Modular Building: Case study and prototype of an open source modular system using rapid \\ prototyping
}

\author{
Cristiana Griz \\ Universidade Federal de Pernambuco, Brasil \\ crisgriz@gmail.com \\ Natália Queiroz \\ Universidade Federal da Paraíba, Brasil \\ nataliaqueiroz.arq@gmail.com
}

\author{
Carlos Nome \\ Universidade Federal da Paraíba, Brasil \\ carlos.nome@gmail.com
}

\begin{abstract}
This paper presents the research development for a base structural module for the Casa Nordeste project. Casa Nordeste is a compact housing experiment that will participate in the Solar Decathlon Latin America competition. It consists of a modular building that houses living, cooking, and sanitizing space. Developments presented are based on digital design and fabrication principles and processes, through algorithms that allow its customization. In this sense, discussions begin with a brief theoretical discussion about the concepts that underline the project: evolutionary housing; digital technologies that improve design and construction; open source construction and generative design systems. The paper finalizes by presenting and discussing developments of three different design aspects of the structural module: (a) geometry of the frames, (b) its modulation, and (c) fittings and joining mechanisms.
\end{abstract}

Keywords: Digital fabrication; Rapid prototyping; Visual programming; Compact housing.

\section{Introdução}

Este artigo trata sobre estruturas modulares desenvolvidas para construção de habitações compactas por meio de processos de parametrização e fabricação digital. Em especial, tange o tema da habitação de interesse social (HIS), e investiga a questão da sua personalização, variação de tipos espaciais, aliando o uso das tecnologias digitais tanto no processo projetual, quanto na fabricação da habitação.

O déficit habitacional no Brasil e situações emergenciais torna urgente a definição de sistemas estruturais para o desenvolvimento de projetos de qualidade, com baixo impacto ambiental, e a custos acessíveis. Com o intuito de construir uma solução para esta questão, o Laboratório de Modelos + Prototipagem $(\mathrm{LM}+\mathrm{P})$ da UFPB vem desenvolvendo a pesquisa Casa Nordeste, com o propósito de participar do Solar Decathlon América Latina e Caribe - competição internacional que promove pesquisa para o desenvolvimento de casas eficientes. O objetivo é projetar uma habitação de baixo custo, que contemple a máxima eficiência em termos de conforto e rendimento, que atenda os princípios de uma casa evolutiva, desenvolvida com produtos, materiais, e tecnologias do nordeste brasileiro, seguindo os princípios de construção em código aberto.

Nesse sentido, os princípios projetuais norteadores do projeto da Casa Nordeste são:
- Atender às necessidades específicas do nordeste brasileiro, apesar de permitir sua adoção em outras localidades;

- Adequar-se ao conceito de habitação evolutiva (Brandão, 2011);

- Atender a uma família hipotética, definida por técnica de cenário, com problemática sorteada;

- Ser projetada, prototipada, fabricada digitalmente, seguindo os princípios de código aberto.

Assim, optou-se por uma construção modular que evolui ao longo de um terraço - elemento típico da arquitetura nordestina, construída com base na adaptação do sistema de código aberto proposto pelo Wikihouse (comentado mais detalhadamente a seguir).

Segundo Brandão (2011), uma habitação é considerada evolutiva quando, dada a maneira como foram concebidos os seus espaços, permite aumenta-los, alterar os usos, ocupá-la de maneiras variadas, distribuindo as funções diferentemente - ou seja, é preciso que ela permita que seus espaços possam ser customizáveis. Como o habitar contemporâneo é inevitavelmente dinâmico, devido, dentre outros fatores, à mudanças na constituição familiar, é preciso que a edificação apresente certo nível de flexibilidade para permitir customizações. Assim, a aplicação do conceito de casa evolutiva para o projeto da Casa Nordeste responde bem a essa questão através do uso de módulos conectáveis, que permitem a expansão ou contração da habitação, conforme demandas dos usuários. 
Como comentado, além dessa premissa da casa evolutiva, o projeto se desenvolve seguindo os princípios de construção em código aberto - os chamados open sources. Esse se configura em um modelo de desenvolvimento compartilhado, que promove o livre acesso a informações, estimulando seu uso e adaptação. As tecnologias colaborativas abertas surgem de uma tendência contemporânea de liberação da informação como forma de promover o conhecimento e aprimoramento continuado. Aplicações como estas em arquitetura oferecem oportunidades para ultrapassar barreiras geográficas e digitais, por vezes limitada processos e a profissionais locais, alcançando um público que nunca antes teve acesso a projetos concebidos com para execução através do uso de variadas tecnologias contemporâneas.

Tendo essa problemática como motivação, o objetivo deste artigo é mostrar o desenvolvimento de um módulo estrutural base da Casa Nordeste, através de algoritmos que permitam sua customização. Trata-se de um módulo que abriga espaços destinado às atividades de: comer, cozinhar, higienizar-se e dormir.

Sendo assim, são explorados três níveis distintos do módulo estrutural: (a) a geometria dos pórticos, (b) a modulação e, por fim, (c) os encaixes e mecanismos de união. Os dois primeiros são desenvolvidos a partir de algoritmos. O último está em fase de estudo e prototipagem, conforme é apresentado mais adiante.

\section{Sobre a teoria}

A revisão apresentada por este artigo aborda quatro temas principais: a prototipagem e a fabricação digital, o sistema Wikihouse (já que este serviu de base para o desenvolvimento da estrutura), a gramática da forma e a programação visual ambas para permitir e facilitar a customização de projetos. Os temas são a base teórica para o desenvolvimento da Casa Nordeste.

$\mathrm{Na}$ sequência, são explorados processos de projeto analógicos e digitais, além do uso de prototipagem rápida (PR) em preparação para a fabricação digital (FD). Tanto a PR, quanto a FD dependem de equipamentos controlados numericamente por computador (CNC) que executam elementos físicos (Iwamoto, 2009).

De acordo com Pupo (2009), os métodos de produção digital apresentam finalidades e maneiras distintas para produzirem elementos físicos. Em relação à finalidade, os elementos produzidos digitalmente podem ser protótipos ou o próprio produto final. Os primeiros (resultados da prototipagem rápida) são destinados à produção de modelos, em escala real ou reduzida, que podem auxiliar na concepção e avaliação do projeto, bem como servir para apresentação da solução projetual. Já os produtos finais (resultado da fabricação digital) são elementos produzidos para serem utilizados diretamente na edificação (no caso do projeto de arquitetura), desde formas para executar parte do edifício, passando por pequenas partes deste, até a sua totalidade.

\footnotetext{
${ }^{1}$ A envoltória de um edifício é composta por elementos de vedações verticais e horizontais.
}

Em relação a maneira em que esses elementos são produzidos, a autora destaca basicamente dois tipos: o aditivo e o subtrativo. O primeiro se utiliza de equipamentos onde 0 objeto é produzido a partir da sobreposição de camadas de materiais diversos (sólidos, líquidos, lâminas, pós), obtido, principalmente pelas impressoras 3D. Já o método subtrativo se caracteriza pela obtenção de elementos feitos pelo desgaste do material, resultado de equipamentos como a cortadora a laser e a fresadora CNC (Pupo, 2009).

Assim como feito em outras experiências brasileiras (Pássaro, Rohde, 2014; Nardelli, Backheuser, 2016), para a Casa Nordeste optou-se pela adaptação do sistema de construção em código aberto Wikihouse (Wikihouse, 2017). Trata-se de um sistema composto por peças de madeira compensada cortado a partir de processos subtrativos em ferramentas CNC. O ensamble se dá através de encaixes para facilitar a montagem da casa.

Desenvolvido pelo escritório Architecture 00 em parceria com Momentum Structural Engineers, o Wikihouse é uma plataforma em código aberto que apresenta três áreas de atuação: o desenvolvimento de um plugin para software gratuito que facilita o desenvolvimento do projeto; a construção de protótipos em escala real e; o desenvolvimento estrutural em madeira cortada na fresadora CNC e montadas com travamentos nas três direções. Este sistema dispensa parafusos ou colas e opera através de uma plataforma virtual colaborativa, compartilhada e aberta para troca de informações. A escolha por um sistema construtivo análogo a esse para a Casa Nordeste se justifica pelas suas próprias premissas: o uso de materiais baratos, recicláveis ou biodegradáveis, a facilidade de montagem e a fácil adaptação do projeto para climas, culturas e economias diferentes, proporcionando um projeto de qualidade a um preço acessível.

Com essas características, o sistema Wikihouse possui potencial para beneficiar comunidades de baixa renda e construtores de HIS, à medida em que se utiliza de materiais e equipamentos de fácil acesso e montagem. Assim, tanto a estrutura, quanto a envoltória ${ }^{1}$ da Casa Nordeste serão análogas a esse sistema construtivo. No entanto, a envoltória também deverá atender a questões de localidade para o clima quente e úmido do nordeste brasileiro.

Outra vantagem de tomar como base o wikihouse é que sua abordagem favorece a customização em massa de projetos. Isto é, permite oferecer produtos personalizados, em grandes quantidades, a custos similares aos de produtos padronizados e disponibilizados por meio da produção em massa (Duarte, 2007). Prática já consolidada nas indústrias automotiva, aeronáutica e naval, a customização em massa aplicada a projetos unidade habitacionais pode trazer benefícios financeiros tanto para o cliente, quando para o construtor (Naboni, Paoletti, 2015).

Pensando nisso, e baseado na Wood Frame Grammar (Lass, 2006), tanto o projeto da estrutura quanto o da envoltória, serão desenvolvidas através de um sistema generativo de projeto. O projeto generativo é uma metodologia projetual que 
tem foco no processo de projeto do qual decorre o produto que está sendo projetado (Fischer;Herr, 2001). É um método indireto de projeto, no qual o projetista não se preocupa apenas com a solução de um problema em particular em um contexto específico, mas em criar uma codificação dos parâmetros projetuais de maneira genérica, que possibilite resolver problemas semelhantes em contextos diferentes (Celani, 2011).

Um dos sistemas generativos de projeto é a gramática da forma. Trata-se de um sistema de geração de formas baseado em regras e que pode ser descrito como um sistema de algoritmos para criar e entender projetos diretamente através de computação com formas (Knight, 2000), ou, como sugere Eloy (2012), é uma série de regras que são aplicadas passo a passo a formas para gerar uma linguagem de projeto.

Nesse sentido, com o intuito de alcançar certo nível de personalização, serão criadas duas gramáticas: uma para definição formal da estrutura, foco deste artigo, outra para concepção da envoltória. Cada uma dessas gramáticas terá suas próprias especificidades e deverá atender a todos os princípios projetuais propostos para o projeto.

Já pensando na customização tanto da estrutura, quanto da envoltória, o estudo volumétrico inicial da Casa Nordeste (mostrado a seguir) já prevê a adoção de vários tipos de perfis estruturais. Também são consideradas variações nas suas quantidades e posicionamento, que podem mudar conforme a evolução dos módulos da casa. Nesse sentido, para explorar variações estruturais, lógicas distintas de segmentação de componentes e de junções, o módulo inicial da Casa Nordeste está sendo desenvolvida em softwares de Programação Visual - o Grasshoper e o Dynamo.

Programação Visual permite criar scripts, concatenando elementos gráficos e não necessariamente usando linguagem de código de texto. Quando esse tipo de programação é aplicado gera um modelo visual de fluxo de dados. Esse tipo de abordagem associado a um programa de modelagem vem se tornando popular entre projetistas, porque permitem a criação de processos variados e integrados conforme interesse projetual.

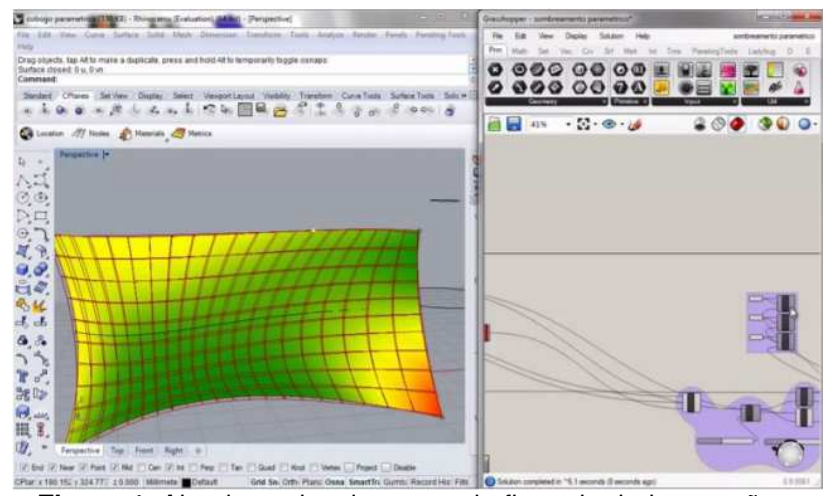

Figura 1. Algoritmo visual mostrando fluxo de dados e ações. Fonte. Queiroz, 2015.

A vantagem dessa abordagem é a possibilidade de executar modelos semelhante a ambientes algorítmicos de modelagem sem necessidade de usar código no texto, criando um ambiente paramétrico. Em vez de apresentar uma interface para escrever linhas em um compilador, esses programas contêm uma área de trabalho onde se insere os componentes que comporão a rotina (ou, na linguagem de programação, script) para realizar uma determinada tarefa (Celani e Vaz, 2012).

Os softwares de programação visual possibilitam que as operações de modelagem sejam controladas, otimizadas e automatizadas pelo usuário, através da criação de scripts. O modelo visual do fluxo dos dados nesses scripts (Figura 1) é demonstrado com base em nós (funções computacionais que executam determinada ação) e links (input - dados de entrada, e output - dados de saída). De maneira geral, um ou mais nós representam uma etapa da modelagem. Cada nó possui um input específico e, após a execução da ação de modelagem, gera um output. Este último, pode servir de novo input para outros nós, que representam outras etapas da modelagem que compõem a rotina. Assim, todo o processo gera um diagrama que mostra o sistema de fluxo de dados gerados (Janssen e Wee, 2011). Segundo Florio (2017),

Todo o processo depende, fundamentalmente, de como se organiza a sequência de nós constituídos por restrições e parâmetros. A ordem dos nós, ao ser alterada, pode implicar em profundas alterações na geometria que constitui os elementos construtivos parametrizados. A segunda observação é que para definição dos nós é necessário ter conhecimentos-chave que possam ser condensados nele. Sem dúvida, estes conhecimentos devem vir de experiências anteriores do arquiteto, ou a partir de estudos de caso de outros arquitetos.

A incorporação de ciclos avaliativos ao processo de projeto, associado ao design paramétrico, possibilita maior liberdade para ajustes e elaboração de combinações variadas como resposta a um mesmo problema. Esta combinação acaba por expandir o controle do usuário frente aos limites impostos pelas ferramentas de modelagem tradicionais. Colaborando com a compreensão do projetista, e computando padrões que podem ser utilizados para estabelecer soluções (Queiroz, 2015).

\section{Sobre o método e etapas}

As etapas de desenvolvimento previstas para a Casa Nordeste são descritas a seguir:

1. Elaboração de protótipos feitos com a cortadora a laser, de modelos disponíveis no site Wikihouse visando entender e as particularidade do sistema construtivo;

2. Desenvolvimento de um algoritmo para a concepção preliminar da estrutura;

3. Desenvolvimento de um algoritmo para a concepção preliminar do sistema de encaixes para a estrutura;

4. Identificação dos componentes necessários para o desenvolvimento das gramáticas da estrutura e da envoltória.

5. Desenvolvimento e implementação das gramáticas;

6. Elaboração de novos protótipos baseados na adaptação do sistema construtivo;

7. Desenvolvimento de um algoritmo para a concepção preliminar do envoltório; 
8. Desenvolvimento implementação da gramática da envoltória;

9. Elaboração de protótipos com soluções geradas pelas gramáticas;

10. Fabricação e construção da Casa Nordeste.

Como dito, este artigo se dedica aos estágios iniciais do desenvolvimento do módulo estrutural mínimo da Casa Nordeste. Nesse sentido, o foco dos trabalhos a serem apresentados a seguir abarca as três primeiras etapas apresentadas acima.

\section{Protótipo da Microhouse}

Com o intuito de entender as particularidades do sistema wikihouse de construção, foi executado um modelo em escala utilizando o método subtrativo de produção digital - a cortadora a laser. Utilizando um dos modelos disponibilizados no site a Microhouse, foi possível compreender questões como: os encaixes, sua execução e desperdício gerado pelos cortes.

Como comentado, o sistema wikihouse funciona com peças estruturais em madeira, unidas por encaixes, sem ser necessário parafusos ou colas. A estrutura é feita através de quadros travados por peças transversais que se cruzam por orifícios no próprio quadro e são fixadas com cunhas. É assim que o sistema trava a estrutura nas três direções. Já o esqueleto da estrutura é contraventado com a fixação de chapas de compensado de fechamento - as paredes internas e externas da envoltória, que se encaixam em abas da estrutura (Figura 2)

O quadro é formado por um "sanduíche" de duas placas de madeira. Nas suas juntas, há um reforço com uma terceira placa para que o quadro fique mais rígido. Nas duas placas externas do quadro ficam os orifícios onde são encaixadas as placas da envoltória.

Para execução do protótipo optou-se pelo papel Paraná. Este material foi escolhido por ser econômico, comercializado em várias espessuras, de fácil manuseio e de baixa toxicidade em decorrência da queima. Assim, para que o protótipo ficasse exatamente na escala 1/10, a espessura adotada do papel Paraná foi de $2 \mathrm{~mm}$.

As peças que formam os três módulos da Microhouse foram identificadas e organizadas em pranchas com a dimensão máxima da máquina de cortadora a laser - $30 \times 60 \mathrm{~cm}^{2}$. Após o corte, as peças foram separadas para a montagem do protótipo (Figura 2), feito por alunos e professores envolvidos no projeto, de maneira a capacitar toda a equipe, tanto no tipo de método de fabricação digital, quanto na lógica de encaixe do sistema wikihouse.

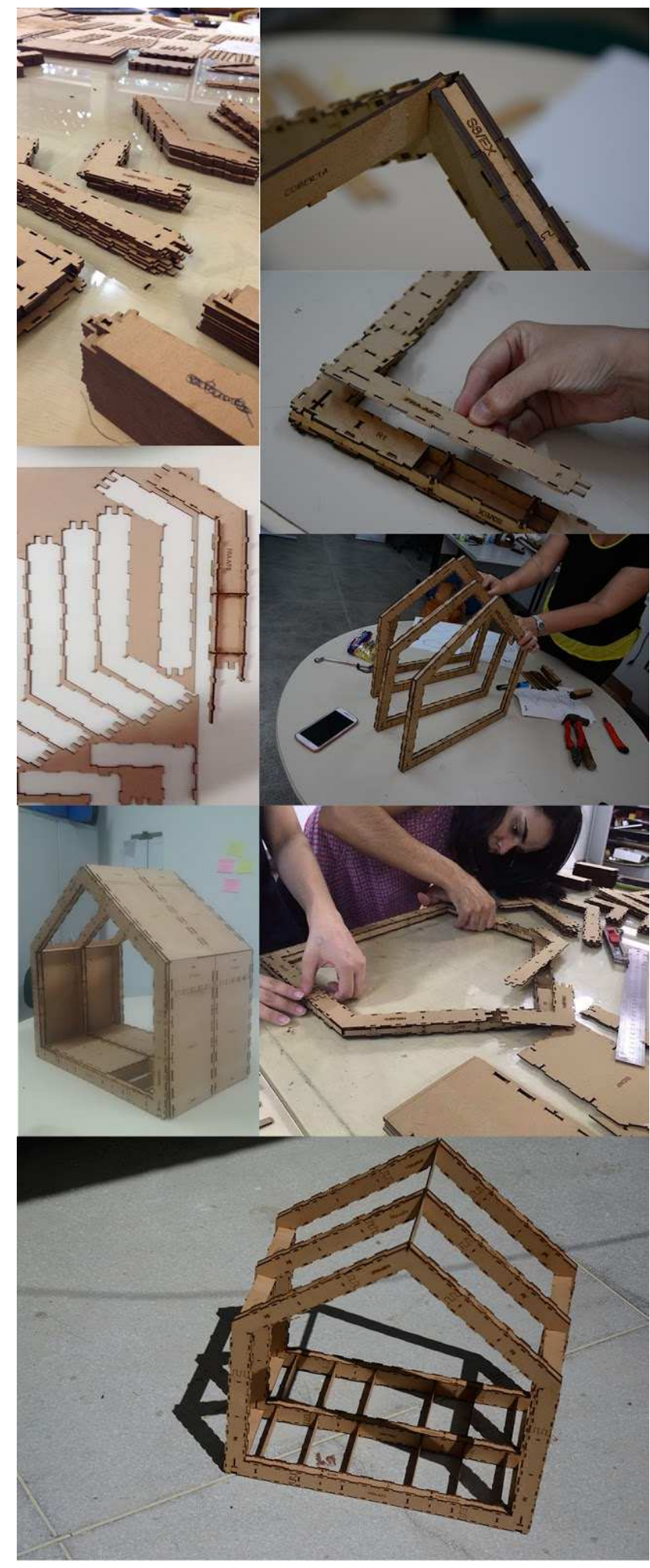

Figura 2: Construção do protótipo em escala de um módulo da Wikihouse.

\footnotetext{
2 Para o corte, foi feita uma parceria com o L.O.U.Co (Laboratório de Objetos Urbanos Conectados), do Porto Digital, que nos disponibilizou a Cortadora laser PROTEC speed 100.
} 
Como resultado do experimento, foi possível verificar que a adoção de encaixes em três direções com múltiplas placas promove um bom travamento da estrutura. No entanto dificultam um pouco o processo de montagem, além de gerar resíduos pouco aproveitáveis (Figura 2). Notou-se ainda que a adoção de peça contínuas nas esquinas permite maior rigidez à estrutura. Porém, o processo de alinhamento das placas para corte requer mais atenção para evitar desperdícios de material. A codificação das peças, bem como os diagramas de montagem foram vitais para a montagem bem sucedida do protótipo. No entanto, devido à alta umidade no local de montagem, houve uma dilatação do papel Paraná o que dificultou a montagem do modelo. Para superar esse inconveniente, serão explorados outros materiais em protótipos futuros.

Através do protótipo de estudo, cabem três questões como recomendações para a Casa Nordeste. Primeiro, a exploração de encaixes mais simples e otimizados; segundo a minimização de recortes menores ou detalhes; e por fim, a modulação de peças já considerando padrões de alinhamento em função das dimensões comercias disponíveis das placas de compensado para evitar sobras e desperdício.

\section{Concepção preliminar da estrutura da Casa Nordeste}

Esta seção se dedica a apresentar discussões guiadoras do projeto Casa Nordeste, tendo em vista a utilização de um sistema inicialmente inspirado no wikihouse e a premissa de desenvolver o projeto digitalmente.

Em relação à estrutura, as modificações do sistema wikihouse foram pensadas de maneira a adapta-la para edificações com até três pavimentos. No lugar de quadros, serão usados pórticos, também formados por peças de encaixe, e piso com viga vagonada paralelo ao pórtico (resolvendo assim, o contraventamento).

Como comentado, a intenção é que tanto o projeto da estrutura, quanto da envoltória possam ser customizáveis, além de poderem variar conforme a evolução dos módulos que formam a edificação (Figura 3). É justamente através do uso de módulos conectáveis, que o projeto faz uso do conceito de habitação evolutiva, através da expansão ou contração da habitação - artifício que também facilita a customização de projetos.

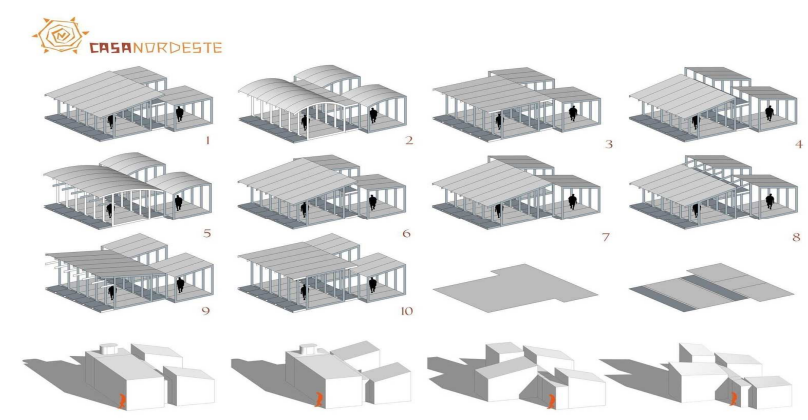

Figura 3: Estudos volumétricos feitos no Skecthup.
Em decorrência da busca por uma simplificação dos cortes e redução do desperdício, houve considerações de projeto que o distinguiram do sistema Wikihouse. Primeiro, e o principal, admitiu-se o uso de cola para o sistema Casa Nordeste. Os pórticos serão formados pela junção de duas ou mais placas (por colagem), a serem definidas em testes de resistência, sendo as emendas necessárias feitas por encaixes. Além disso, o espaçamento entre pórticos e os cortes é dimensionado de maneira a proporcionar maior economia e aproveitamento do material, de acordo com o tamanho da placa de madeira compensada disponível no mercado. Sendo a dimensão da placa, o dado de entrada inicial para a elaboração do modelo paramétrico (programação visual).

Como dito, o algoritmo definidor da estrutura do módulo deve ser desenvolvido em três níveis: a geometria dos pórticos; sua repetição e modulação; e, os encaixes e mecanismos de união. Com intuito de disponibilizar a lógica do sistema em um maior número de plataformas, os scripts foram elaborados em duas ferramentas: Dynamo para Revit (BIM ${ }^{3}$ mais programação visual) e Grasshopper para Rhinoceros 3D (somente programação visual).

Os três níveis de desenvolvimento do algoritmo serão feitos em ambos os softwares em paralelo. No entanto, como os scripts ainda estão em fase de desenvolvimento, são apresentados neste artigo os resultados preliminares apenas daqueles desenvolvidos para gerar a geometria dos pórticos e sua modulação. Ao final, é abordado a construção dos protótipos para os primeiros testes comparativos dos encaixes, no que tange a redução de desperdício e o tempo de corte.

Visto que uma das exigências da competição Solar Decathlon para a habitação proposta é a modelagem BIM, é natural a exploração de ferramentas que potencializam sua integração com softwares que trabalham com processos algorítmicos. Estes processos podem gerar variações formais de maneira ágil, as quais podem ser convertidas em componentes de um modelo BIM. Tais componentes passam a figurar em relatórios variados, como, quadros, tabelas quantitativas ou documentos gráficos. Esta combinação permite, portanto, avanços na produção documental do projeto sem interromper o desenvolvimento e refinamento dos algoritmos definidores dos processos de fabricação da Casa Nordeste.

\section{Modelagem usando BIM + programação visual}

Em plataforma BIM, o intuito é modelar a geometria do pórtico, seu padrão de repetição, além da inserção, ainda que esquemática, dos painéis da envoltória (piso, parede e teto) tudo de maneira paramétrica. Para tanto, foi utilizado o Dynamo, que interage com o software de tecnologia BIM - o Revit.

Para a volumetria inicial da Casa Nordeste, foram modelados os pórticos e os painéis referentes à parede, ao piso e ao teto como famílias carregáveis do Revit. Os parâmetros concebidos para qualquer perfil de pórtico permitem mudanças no vão, na altura dos componentes verticais (que altera, automaticamente, a inclinação da coberta) e na largura das peças (formada por colagem de placas de compensado).

3 Modelagem da Informação da construção (do inglês Building Information Modeling). 
Já os parâmetros dos painéis são referentes a sua largura e comprimento e inclinação (este último, no caso das placas que formam o teto).

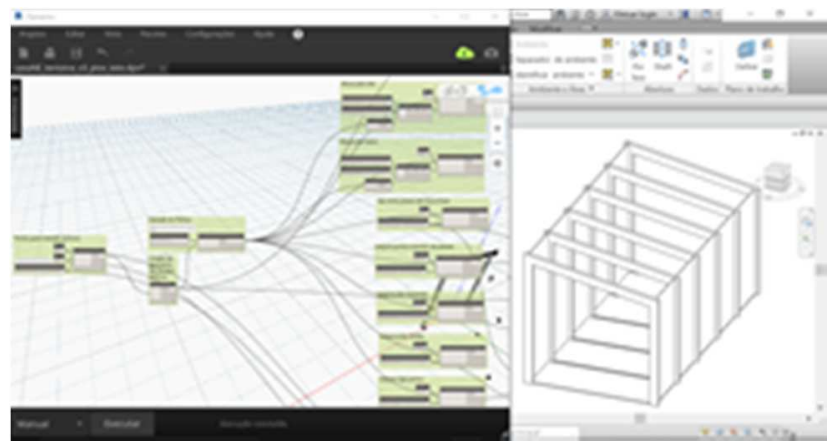

Figura 4: Rotina para criação do volume da Casa Nordeste, com a inserção dos painéis das paredes e do piso. Visualização da geometria no Revit.

Além do usuário poder manipular os parâmetros criados juntamente com as famílias de cada perfil de pórticos (que possibilita a mudança no seu formato), a rotina desenvolvida no Dynamo permite também a manipulação automática do espaçamento e do número de pórticos. Para a inserção dos painéis de piso, parede e teto, a rotina é desenvolvida de maneira que: (i) a largura seja atrelada diretamente à dimensão do espaçamento e da largura dos pórticos; e (ii) o comprimento mude automaticamente de acordo com o vão do pórtico (Figura 4).

A princípio, foram feitas duas geometrias distintas de pórticos (Figura 5), para demonstrar que, na rotina, podem ser aplicados vários perfis de pórtico, de maneira a gerar uma maior variação formal para a edificação. Já os painéis são volumetrias simples, que, futuramente poderão apresentar distintos formatos e detalhes.

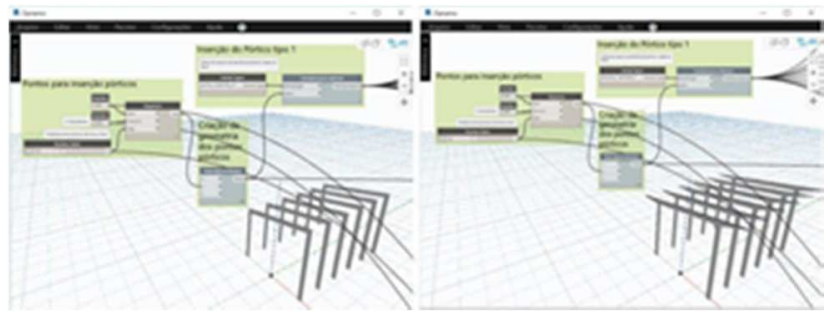

Figura 5: Rotina para criação do volume da Casa Nordeste, com a utilização de dois pórticos distintos e visualização da geometria no workspace do programa.

\section{Modelagem usando apenas programação visual}

O modelo elaborado no Grasshopper usa como parâmetro inicial o tamanho da placa de compensado. A lógica é que todos os dimensionamentos necessários para criação dos pórticos, cortes e modulação utilizem esses parâmetros iniciais como referência, evitando assim, desperdício nos cortes e aproveitamento máximo das placas. Exemplo: a seção e altura do pórtico possuem dimensões que são dividendos simples em relação às dimensões das placas de compensado. Isso garante cortes sequenciais e aproveitamento máximo das placas.
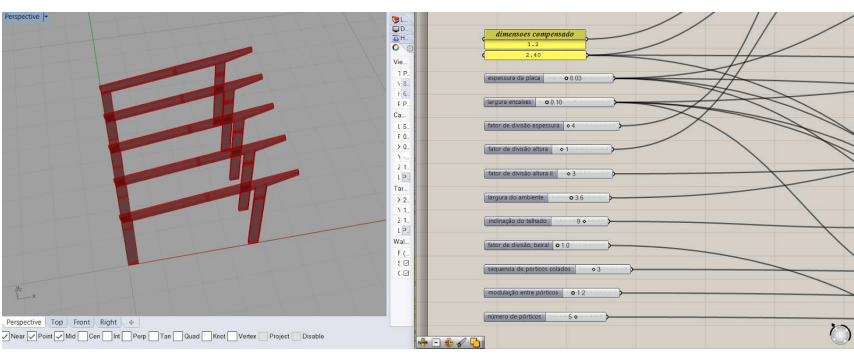

Figura 6: Modelo gerado em Grasshopper mostrando parâmetros que possibilitam mudanças incrementais.

O Grasshopper, diferente do Dynamo, requer que o modelo seja inteiro construído em um único ambiente computacional, chamado de canvas. Essa característica faz com que seu script seja inerentemente maior que o gerado no Dynamo. As mudanças incrementais do modelo são realizadas utilizando os parâmetros do script, organizados todos em uma única coluna (Figura 6).

Tabela 1. Parâmetros que permitem mudanças incrementais do modelo gerado em Grasshopper.

Inputs iniciais: dimensão da placa de compensado e espessura

\begin{tabular}{|l|l|l|}
\hline \multicolumn{3}{|c|}{ Parâmetros em cada fase } \\
\hline $\begin{array}{l}\text { Geometria dos } \\
\text { pórticos }\end{array}$ & \multicolumn{1}{|c|}{ Modulação } & \multicolumn{1}{|c|}{ Encaixes } \\
\hline $\begin{array}{l}\text {-Altura do } \\
\text { ambiente; } \\
\text {-Inclinação da } \\
\text { cobertura; } \\
\text {-Tamanho do } \\
\text { beiral } \\
\text {-Seção do } \\
\text { pórtico (largura). }\end{array}$ & $\begin{array}{l}\text {-Sequência de } \\
\text { pórticos para } \\
\text { colagem; } \\
\text {-Número e distância } \\
\text { entre pórticos; } \\
\text {-Largura do } \\
\text { ambiente. }\end{array}$ & $\begin{array}{l}\text {-Largura da zona } \\
\text { destinada aos } \\
\text { encaixes.; }\end{array}$ \\
\hline
\end{tabular}

A configuração dos pórticos permite mudanças nas três fases de desenvolvimento. Sendo que a fase da geometria do pórtico é referente à altura, a inclinação da coberta, ao tamanho do beiral e à seção do pórtico. A fase de modulação permite mudanças no número de sequência de pórticos para colagem entre si (Figura 7), modulação entre pórticos colados e largura do ambiente. A terceira fase, dos encaixes, ainda está em fase de finalização. No entanto, o script está sendo concebido de maneira a identificar zonas onde haverá necessidade de encaixes em decorrência das limitações dos tamanhos das placas de compensado (Figura 7). A largura dessas zonas também é um componente paramétrico, controlado pelo usuário (Tabela 1). 


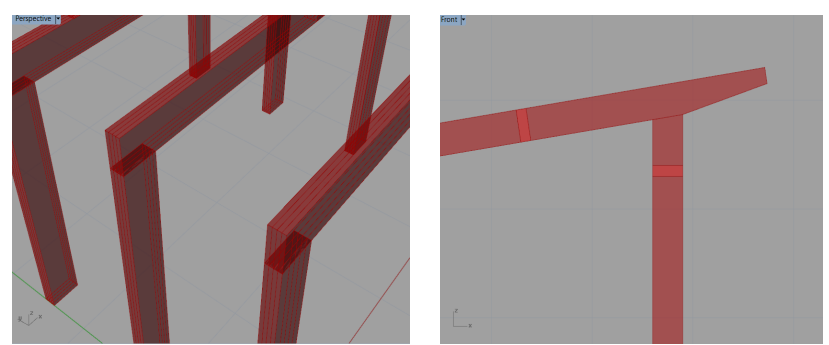

Figura 7: Detalhes. A imagem da esquerda mostra zonas onde será necessário encaixe. A imagem da direita mostra sequência de pórticos colados.

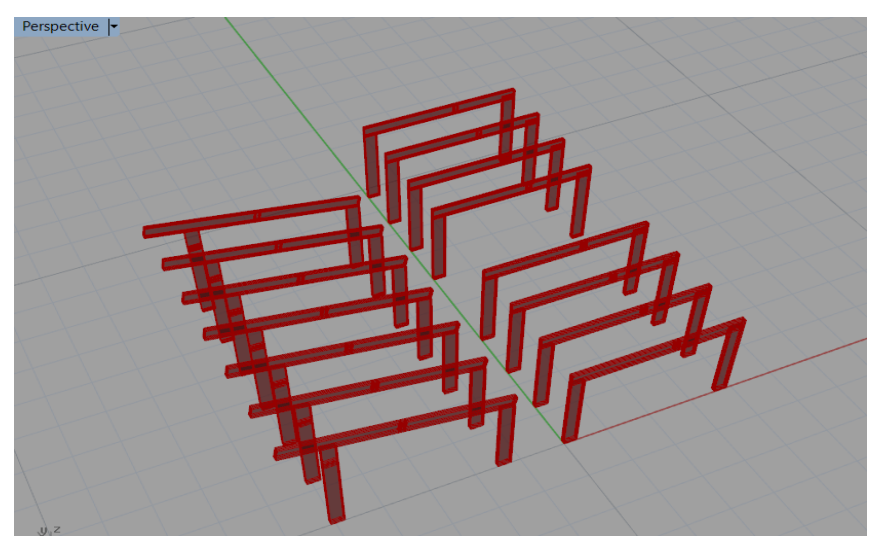

Figura 8: Combinação estabelecida através do script.

Através do script é possível elaborar diversas combinações de maneira rápida e automatizada (Figura 8). As etapas futuras incorporaram fundação, a automatização do encaixe, e dos painéis de envoltória.

\section{O sistema de encaixes}

O estudo dos encaixes entre peças visa a otimização do processo de corte dos protótipos em Fresa CNC, a partir de três questões centrais que emergiram da análise do modelo da Microhouse. Primeiro, a necessidade de otimizar os encaixes, visto que o alinhamento "nesting" das peças gera desperdício. Segundo, a otimização do passo da fresa para a oportunizar a redução de tempo e custo de corte. E, por fim, a definição de parâmetros para o algoritmo de geração dos encontros.

Para avaliação do desenvolvimento foi efetuado o comparativo entre duas formas de encaixe (Figura 10). Um análogo à Microhouse e o proposto para a Casa Nordeste. O comparativo consistiu em alcançar um retângulo de 5 por 10 milímetros a partir do encaixe entre duas peças cortados em uma fresadora CNC. A forma desenvolvida permite o encaixe entre segmentos lineares com uma redução significativa na extensão do passo. No caso estudado esta redução chega a $15 \%$ do perímetro da peça (Figura 9).

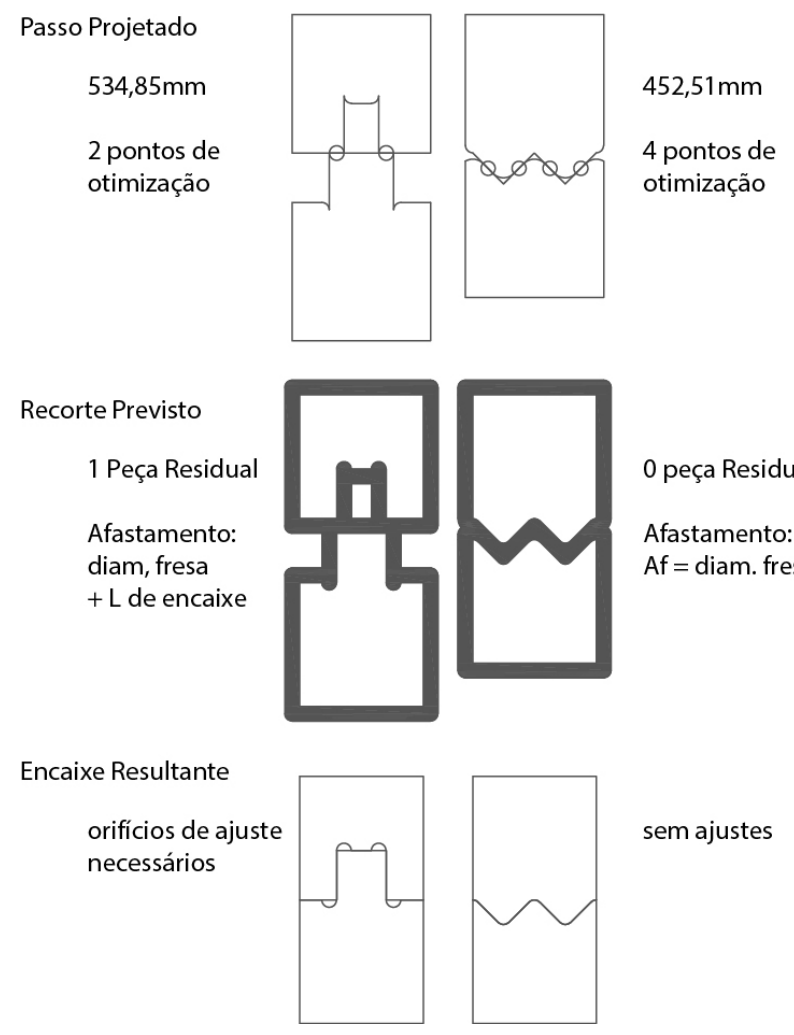

Figura 9: Perfis dos recortes dos encaixes.

O encaixe proposto resulta de uma abordagem que considera em primeiro plano os atributos e potenciais da ferramenta de corte CNC escolhida. Assim sendo, o foco foi o projeto do passo de corte. Foram considerados o diâmetro da fresa, os ângulos de encaixe, o eixo de passo, bem como os ajustes de passo para encaixe.

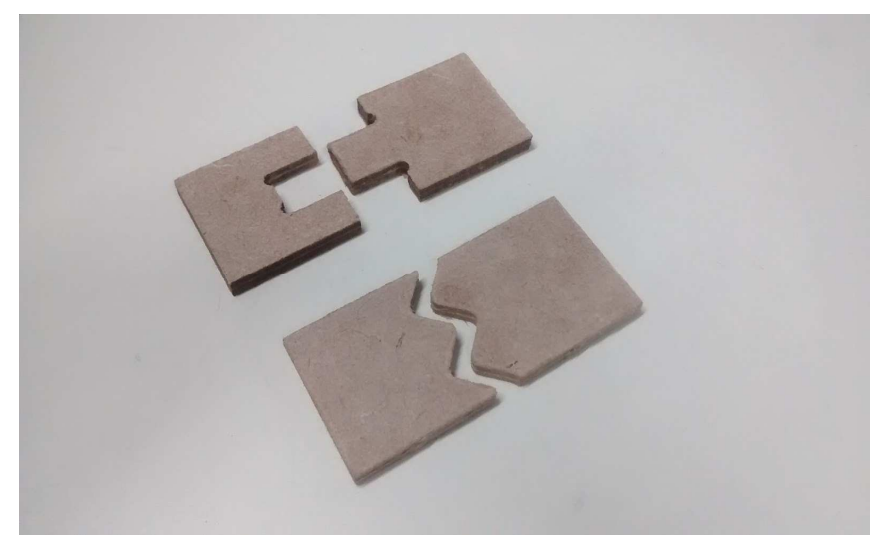

Figura 10: Protótipos de encaixes com passo otimizado, cortados em fresadora CNC. 


\section{Considerações finais.}

O estudo apresenta como resultado a descrição de um processo que se inspira em um sistema open source - 0 Wikihouse. Apresenta conceitos norteadores do projeto Casa Nordeste, bem como descreve ferramentas e modelos digitais, além de planos de execução de protótipos no contexto de prototipagem rápida visando fabricação digital.

O uso de programação visual permitiu estabelecer um sistema lógico baseado em princípios de racionalização e fabricação, capaz de gerar inúmeras combinações distintas a partir da matéria-prima. Uma vez estabelecido, pode ser utilizado, não apenas para Casa Nordeste, mas também para qualquer outra proposta correlata. Passos futuros preveem incorporação e automatização dos encaixes e pranchas de corte, bem como aprofundar a otimização dos processos de alinhamento das peças.

O conceito de construção modulada aliada ao de habitação evolutiva pode ir muito mais além das questões habitacionais. A construção de um módulo de serviços neste formato, por exemplo, pode atender a diversas situações. Por se tratar de uma solução rápida e com baixo custo, em que as peças podem ser cortadas e montadas em pouco tempo, esse módulo também pode atender a situações emergenciais, a canteiros de obra diversos, a eventos que necessitam de instalações desmontáveis, dentre outros.

\section{Agradecimentos}

Os autores agradecem a Capes, pelo suporte financeiro através do Programa Nacional de Pós-doutorado (PNPD/CAPES), ao L.O.U.Co (Laboratório de Objetos Urbanos Conectados, do Porto Digital), pela parceria na utilização da cortadora a laser; e ao Prono 3D, da UFSC, pelo suporte na compreensão dos processos associados ao uso da fresadora CNC.

\section{Referências}

Brandão, D. (2011). Disposições técnicas e diretrizes para projeto de habitações sociais evolutivas. In Ambiente Construído, v. 11, n. 2 , p. 73-96, abr./jun.

Celani, C. (2011). Algorithmic Sustainable Design. Vitruvius, v.116. Disponível http://www.vitruvius.com.br/revistas/read/resenhasonline/10.116/ 3995

Celani, G.; Vaz, C. CAD scripting and visual programming languages for implementing computational design concepts: A comparison from a pedagogical point of view. International Journal of Architectural Computing, v. 10, n. 1, p. 121-138, 2012. ISSN 14780771.

Duarte, J. P. (2007). Personalizar a habitação em série: Uma Gramática Discursiva para as Casas da Malagueira do Siza. Lisboa: Ed. Fundação Calouste Gulbenkian.

Eloy, S. (2012) A transformation grammar-based methodology for housing rehabilitation: meeting contemporary functional and ICT requirements. (PhD). Universidade Técnica de Lisboa, Lisboa.

Florio, W. Projeto Paramétrico: transformações da prática de projeto decorrentes da exploração de modelagem por scripts. Modelos em Arquitetura: Concepção e Documentação. Ed. da UFPB. 2017.
Fischer; Fischer, T.; Herr, C. M. (2001). Teaching Generative Design. In 4th International Generative Art Conference, Generative Design. Milão. Disponível em: <http://www.generativeart.com>. Acesso em: 14 abril 2015.

Iwamoto, L. (2009). Digital Fabrications - Architecture and Material Techniques. New York: Princeton Architectural Press.

Janssen, P.; Wee, C. K. Visual dataflow modelling: a comparison of three systems. 2011.

Knight, T. (2000). Shape Grammars in education and practice: history and prospects. International Journal of Design Computing, v. 2.

Naboni, R; Paoletti, I. (2015). Advanced Customization in Architectural Design ans Construction. Milano: Springer, 2015.

Nardelli, E.; Backheuser, L. (2016) Sistema Wikihouse aplicado ao Programa Minha Casa Minha Vida. In XX Congreso de la Sociedad Iberoamericana de Gráfica Digital - SIGRADI, Buenos Aires.

Oliveira, L. (2009). Metodologia para desenvolvimento de projeto de fachadas leves. (Tese). Universidade de São Paulo, São Paulo.

Passaro, A. (2014). CASA REVISTA: um estudo em fabricação digital em busca de transformação social. In Habitar 2014, Belo Horizonte.

Pupo, R.; celani, G. Implementando a fabricação digital e a prototipagem rápida em cursos de arquitetura: dificuldades e realidades. Cuba: Congreso de La Sociedad Iberoamericano, 2008.

Pupo, R. Inserção da PROTOTIPAGEM e FABRICAÇÃO DIGITAIS no processo de projeto: um novo desafio para o ensino da arquitetura. 2009. (Tese). Universidade Estadual de Campinas, Campinas.

Queiroz, Natália. Artefatos geradores de microclima: biomimética, parametrização e prototipagem rápida na busca por soluções bioclimáticas para clima quente e úmido. (dissertação). Recife, 2015.

Sass, L. (2006). A wood frame gramar. A generative system for digital fabrication. In International Journal of Architectural Computer. Issue 1, vol. 4. Abr.

Stiny, G.; Gips, J. (1972). Shape grammars and the generative specification of painting and sculpture In 7th Ifip Congress. Amsterdam. Disponível em: <http://www.shapegrammar.org/ifip/ifip1.html>. Acesso em: 05 nov. 2014

Tedeschi, A. (2011). Parametric Architecture: with grasshopper. Brieza, Le Penseur.

Wikihouse (2017). The future of homes by everyone, for everyone. Disponível em: https://wikihouse.cc/. Acesso em: 07/02/2017. 